\title{
THE CLINICAL STUDY TO ASSESS THE CORNEAL THICKNESS BY USING PACHYMETRY IN VARIOUS TYPES OF REFRACTIVE ERRORS IN AGE GROUP (10 - 40 YRS.)
}

\author{
Elangovan Marudhamuthu1, Savitha², N. Sivakumar ${ }^{3}$ \\ 1Professor, Department of Ophthalmology, Government Dharmapuri Medical College and Hospital, Dharmapuri. \\ ${ }^{2}$ Assistant Professor, Department of Ophthalmology, Government Dharmapuri Medical College and Hospital, Dharmapuri. \\ ${ }^{3}$ Associate Professor, Department of Ophthalmology, Government Dharmapuri Medical College and Hospital, Dharmapuri.
}

\section{ABSTRACT}

\section{BACKGROUND}

The purpose of the study is to measure the corneal thickness in various refractive errors in the age groups 10 - 40 yrs. by using ultrasonic pachymetry and to analyse corneal thickness measured in various refractive errors. The study was conducted in Govt. Dharmapuri Medical College Hospital. The patients attending the Eye Outpatient Department for defective vision due to refractive error were subjected for corneal thickness measurement using ultrasonic pachymetry.

\section{MATERIALS AND METHODS}

Patients screened for refractive error were under the age group of 10 - 40 yrs. Patients underwent dilatation and retinoscopy and post-mydriatic test was done. Patients were prescribed glass for their subjective acceptance. Patients were subjected to corneal ultrasonic pachymetry to measure the corneal thickness in micrometres after putting $4 \%$ xylocaine local anaesthetic drops.

\section{RESULTS}

In our study among 300 patients of refractive error of age group (10 - 40 yrs.) had Mean Central Corneal Thickness (CCT) of 535 micrometres (SD 32) with the range of CCT of 410 - 590 micrometres. Among 300 patients, 160 patients of myopes had corneal thickness of $541 \mathrm{~mm}$ (SD 31) micrometres. Among 300 patients, 32 patients of high myopes had corneal thickness of 537 micrometres (SD 27); 48 patients among 300 patients of myopic astigmatism had average corneal thickness of 512 micrometres SD (37); 32 patients $/ 300$ patients with hypermetropic astigmatism had corneal thickness of 535 micrometres (SD 30). Hypermetropes (60 patients/300 patients) had average corneal thickness of 545 micrometres (SD 34).

\section{CONCLUSION}

Corneal ultrasonic pachymetry measures the thickness of the cornea. There was no correlation between various refractive errors of age group 10 - 40 yrs. and central corneal thickness. Though corneal thickness was observed to be comparatively less, 512 micrometres (SD $37 \mathrm{~mm}$ ), in case of myopic astigmatism. In high myopes, more stromal ablation is needed to achieve optical correction which renders the postoperative cornea even thinner. The corneal flap thickness decreased in thinner corneas and the visual outcomes was slightly worse in thin corneal flap groups. For high myopes, refractive procedures for myopic correction other than LASIK (Laser in situ keratomileusis), might be more important. The use of ultrasound pachymetry in keratoconic corneas is questionable, because of change in refractive index (Inferior Apical Cone). When compared with orbscan II. In conclusion, changes that occurs in the anterior segment as the eyeball elongates in myopia progression included flatter corneal curvature and decreased corneal thickness. These factors should be taken into account before refractive surgeries to prevent progressive corneal ectasia termed iatrogenic keratoconus.

\section{KEYWORDS}

Central Corneal Thickness, Ultrasonic Pachymetry, Micrometre, Laser in Situ Keratomileusis.

HOW TO CITE THIS ARTICLE: Marudhamuthu E, Savitha, Sivakumar N. The clinical study to assess the corneal thickness by using pachymetry in various types of refractive errors in age group (10 - 40 yrs.). J. Evolution Med. Dent. Sci. 2017;6(46):3605-3608, DOI: $10.14260 /$ Jemds/2017/777

\section{BACKGROUND}

Corneal pachymetry is the process of measuring the thickness of the cornea with hand-held ultrasound device in micrometres.

Financial or Other, Competing Interest: None.

Submission 28-03-2017, Peer Review 27-05-2017,

Acceptance 02-06-2017, Published 08-06-2017.

Corresponding Author:

Dr. Elangovan Marudhamuthu,

Professor,

Department of Ophthalmology

Government Dharmapuri Medical

College and Hospital,

Dharmapuri-636701

Tamilnadu, India.

E-mail: malarelangovan80@gmail.com

DOI: $10.14260 /$ jemds/2017/777 of the normal cornea. Newer generation of ultrasonic
Pachymetry (Greek words: Pachos- Thick + Metry- To Measure is the term used for measurement of corneal thickness). The thickness of cornea was first reported in ancient textbooks on physiological optics (Helmholtz and Gullstrand. Pachymetry is a medical device used to measure the thickness of the cornea. It ranges from 0.7 to $0.9 \mathrm{~mm}$ at the limbus and $0.49 \mathrm{~mm}$ to $0.56 \mathrm{~mm}$ at the centre. It is measured by gentle touching the smooth tip of pachymeter probe to surface of the cornea. The thinnest point averaged $0.44 \mathrm{~mm}$ temporal and $0.29 \mathrm{~mm}$ inferior to the apex. Individual thinnest points located $>1.0 \mathrm{~mm}$ inferior represented fewer than $0.5 \%$ pachymeters work by way of corneal waveforms. 


\section{Aim of the Study}

The clinical study to assess the corneal thickness by using pachymetry in various types of refractive errors in age group (10 - 40 yrs.).

\section{Study Centre}

Dharmapuri Medical College Hospital, Dharmapuri.

\section{Study Design}

Descriptive study.

\section{Study Period}

6 Months.

\section{MATERIALS AND METHODS}

\section{Inclusion Criteria}

Patient with Refractive Error in the age group 10 - 40 yrs. of age. Patient with clear cornea.

\section{Exclusion Criteria}

Patient with presbyopia; age group greater than 40 yrs.; patient wearing contact lens; patient with decompensated cornea; patient with previous refractive surgeries; noncompliant patient.

\section{Sample Size}

300 patients.

Measuring the thickness of cornea was done by using contact method ultrasonic pachymetry. Corneal ultrasonic pachymeters are devices that display the thickness of the cornea when an ultrasonic transducer touches the cornea. It functions by measuring the amount of time needed for ultrasound pulse to pass from the one end of the transducer to Descemet's membrane and back to transducer. All patients were screened in OPD with refractive error. History- nature and duration of symptoms noted. Patient's refractive status was noted. Any previous ophthalmic surgery/laser treatment history was noted. Patient underwent detailed systemic and ocular examination. Anterior segment examination with a slit lamp biomicroscopy was done. Then posterior segment examination was carried out by indirect ophthalmoscope with scleral depression. Appropriate cycloplegic drops were used.

Patient underwent retinoscopy and post-mydriatic acceptance was elicited. Patient was given glass prescription for subjective acceptance. Patient was subjected for the assessment of corneal thickness using pachymetry after putting local anaesthetic drops ( $4 \%$ xylocaine drops).

\section{RESULTS}

\begin{tabular}{|c|c|c|c|c|}
\hline $\begin{array}{c}\text { Myopes } \\
\text { (Diopters) }\end{array}$ & $\begin{array}{c}\text { No. of } \\
\text { Patients }\end{array}$ & $\begin{array}{c}\text { Mean } \\
\text { (Microns) }\end{array}$ & $\begin{array}{c}\text { SD } \\
\text { (Microns) }\end{array}$ & $\begin{array}{c}\text { Mean- } \\
\text { 2SD }\end{array}$ \\
\hline$-0.25 \mathrm{D}$ to - 3.0D & 82 & 540 & 33 & 474 \\
\hline$-3.25 \mathrm{D}$ to -6.0D & 46 & 546 & 30 & 486 \\
\hline$>$ 6.25D & 32 & 541 & 29 & 483 \\
\hline All Patients & $\mathbf{1 6 0}$ & $\mathbf{5 4 1}$ & $\mathbf{3 1}$ & $\mathbf{4 7 9}$ \\
\hline \multicolumn{6}{|l}{ Table 1. Stratification of CCT in Myopes } \\
\hline
\end{tabular}

In our study of 160 patients among 300 patients with myopes, average corneal thickness was 541 micrometres (SD 31). In Literature, Tokoro and co-workers, myopic cornea is found to be $0.018 \mathrm{~mm}$ thinner than normal controls. Cho and Lam found that CCT decreases with increasing age, but not with refractive error or corneal curvatures as quoted in Literature, Chang SW, Tsai IL, Hu FR, et al. The cornea in young myopic adults. Br J ophthalmol.1956; 42; 251-266.ref 1 of study.

\begin{tabular}{|c|c|c|c|c|}
\hline $\begin{array}{c}\text { High Myopes } \\
\text { (Diopters) }\end{array}$ & $\begin{array}{c}\text { No. of } \\
\text { Patients }\end{array}$ & $\begin{array}{c}\text { Mean } \\
\text { (Microns) }\end{array}$ & $\begin{array}{c}\text { SD } \\
\text { (Microns) }\end{array}$ & $\begin{array}{c}\text { Mean } \\
\text {-2SD }\end{array}$ \\
\hline -6.25D to -9.0D & 14 & 540 & 30 & 480 \\
\hline -9.25D to-12D & 10 & 538 & 28 & 485 \\
\hline -12.25D to -15D & 6 & 532 & 27 & 494 \\
\hline -15.25D to-18D & 2 & 530 & 13 & 528 \\
\hline All Patients & $\mathbf{3 2}$ & $\mathbf{5 3 7}$ & $\mathbf{2 7}$ & $\mathbf{4 8 7}$ \\
\hline
\end{tabular}

In our study of 32 patients, among 300 patients had high myopia, observed average corneal thickness of 537 micrometres (SD 27). Von Bahr in his study of measurement of corneal thickness found slightly thinner corneas in high myopes. Cho and Lam also quoted thinner cornea in high myopes of non-contact wearers.

\begin{tabular}{|c|c|c|c|c|}
\hline $\begin{array}{c}\text { Myopic } \\
\text { Astigmatism } \\
\text { (Diopters) }\end{array}$ & $\begin{array}{c}\text { No. of } \\
\text { Patients }\end{array}$ & $\begin{array}{c}\text { Mean } \\
\text { (Micro- } \\
\text { metres) }\end{array}$ & $\begin{array}{c}\text { SD } \\
\text { (Micro- } \\
\text { metres) }\end{array}$ & $\begin{array}{c}\text { Mean } \\
\text { 2SD }\end{array}$ \\
\hline $\begin{array}{c}-0.25 \mathrm{D} \text { to 3.0D } \\
\text { (0-180'A) }\end{array}$ & 28 & 520 & 35 & 450 \\
\hline $\begin{array}{c}-3.25 \mathrm{D} \text { to -6.0D } \\
\text { (0-180'A) }\end{array}$ & 20 & 502 & 42 & 418 \\
\hline All Patients & $\mathbf{4 8}$ & $\mathbf{5 1 2}$ & $\mathbf{3 7}$ & $\mathbf{4 3 6}$ \\
\hline \multicolumn{6}{|c|}{ Table 3. Stratification of CCT in Myopic Astigmatism } \\
\hline
\end{tabular}

In our study, 48 patients of the 300 patients were having myopic astigmatism with average corneal thickness of 512 micrometres (SD 37). Comparatively, they had thinner corneas than other refractive errors. This correlates with Von Bahr G's Study Measurements of the thickness of cornea. Archophthalmol 26; 247-266. In our reference study 2 also Price FW, Jr. Koller DL, Price MO (1999)- central corneal pachymetry in patients undergoing laser in situ keratomileusis ophthalmology 106; 2216-2220, also quoted the same. Ref study no-3 in our study.

\begin{tabular}{|c|c|c|c|c|}
\hline $\begin{array}{c}\text { Hypermetropes } \\
\text { (Diopters) }\end{array}$ & $\begin{array}{c}\text { No. of } \\
\text { Patients }\end{array}$ & $\begin{array}{c}\text { Mean } \\
\text { (Micro- } \\
\text { metres) }\end{array}$ & $\begin{array}{c}\text { SD } \\
\text { (Micro- } \\
\text { metres) }\end{array}$ & $\begin{array}{c}\text { Mean } \\
\text { 2SD }\end{array}$ \\
\hline +0.25D to +3.0 D & 46 & 545 & 35 & 475 \\
\hline +3.25D to +6.0D & 14 & 548 & 34 & 478 \\
\hline All Patients & $\mathbf{6 0}$ & $\mathbf{5 4 5}$ & $\mathbf{3 4}$ & $\mathbf{4 7 5}$ \\
\hline \multicolumn{6}{|c|}{ Table 4. Stratification of CCT in Hypermetropes } \\
\hline
\end{tabular}

In our study, 60 patients of the 300 patients were hypermetropes with average corneal thickness of 545 micrometres with SD (34). 


\begin{tabular}{|c|c|c|c|c|}
\hline $\begin{array}{c}\text { Hypermetropic } \\
\text { Astigmatism } \\
\text { (Diopters) }\end{array}$ & $\begin{array}{c}\text { No. of } \\
\text { Patients }\end{array}$ & $\begin{array}{c}\text { Mean } \\
\text { (Micro- } \\
\text { metres) }\end{array}$ & $\begin{array}{c}\text { SD } \\
\text { (Micro- } \\
\text { metres) }\end{array}$ & $\begin{array}{c}\text { Mean } \\
\text { 2SD }\end{array}$ \\
\hline $\begin{array}{c}\text { +0.25D to +3.0D } \\
\text { (0-180'A) }\end{array}$ & 20 & 534 & 30 & 474 \\
\hline $\begin{array}{c}\text { +3.25D to +6.0D } \\
\text { (0-180'A) }\end{array}$ & 12 & 530 & 32 & 466 \\
\hline All Patients & $\mathbf{3 2}$ & $\mathbf{5 3 2}$ & $\mathbf{3 0}$ & $\mathbf{4 7 1}$ \\
\hline \multicolumn{4}{|c|}{ Table 5. Stratification of CCT in } \\
Hypermetropic Astigmatism \\
\hline
\end{tabular}

In our study, 32 patients of the 300 patients were Hypermetropic Astigmatic individuals with average corneal thickness of 532 micrometres, SD (30).

\begin{tabular}{|c|c|c|c|c|}
\hline $\begin{array}{c}\text { Refractive Error } \\
\text { (Diopters) }\end{array}$ & $\begin{array}{c}\text { No. of } \\
\text { Patients }\end{array}$ & $\begin{array}{c}\text { Mean } \\
\text { (Micro- } \\
\text { Metres) }\end{array}$ & $\begin{array}{c}\text { SD } \\
\text { (Micro- } \\
\text { Metres) }\end{array}$ & $\begin{array}{c}\text { Mean } \\
\text { 2SD }\end{array}$ \\
\hline +0.25D to+3.0D & 46 & 540 & 33 & 474 \\
\hline +3.25D to +6.0D & 14 & 546 & 30 & 486 \\
\hline $\begin{array}{c}\text { +0.25D to +3.0D } \\
\text { (0-180'A) }\end{array}$ & 20 & 534 & 30 & 474 \\
\hline $\begin{array}{c}\text { +3.25D to +6.0D } \\
\text { (0-180'A) }\end{array}$ & 12 & 530 & 32 & 466 \\
\hline $\begin{array}{c}\text {-0.25D to -3.0D } \\
\text { (0-180'A) }\end{array}$ & 28 & 520 & 35 & 450 \\
\hline $\begin{array}{c}-3.25 \mathrm{D} \text { to -6.0D } \\
\text { (0-180'A) }\end{array}$ & 20 & 502 & 42 & 418 \\
\hline -0.25D to -3.0D & 82 & 540 & 33 & 474 \\
\hline -3.25D to -6.0D & 46 & 546 & 30 & 486 \\
\hline -6.25D to -9.0D & 14 & 540 & 30 & 480 \\
\hline -9.25D to -12.0D & 10 & 538 & 28 & 485 \\
\hline -12.25D to -15D & 6 & 532 & 27 & 494 \\
\hline -15.25D to -18D & 2 & 530 & 13 & 528 \\
\hline All Patients & $\mathbf{3 0 0}$ & $\mathbf{5 3 5}$ & $\mathbf{3 2}$ & $\mathbf{4 6 9}$ \\
\hline \multicolumn{4}{|c|}{ Table 6. Stratification of CCT } \\
\hline \multicolumn{2}{|c|}{ according to Patient's Refraction } \\
\hline
\end{tabular}

Mean CCT 535 Micrometres with SD 32 Micrometres range 410 - 590 micrometres.

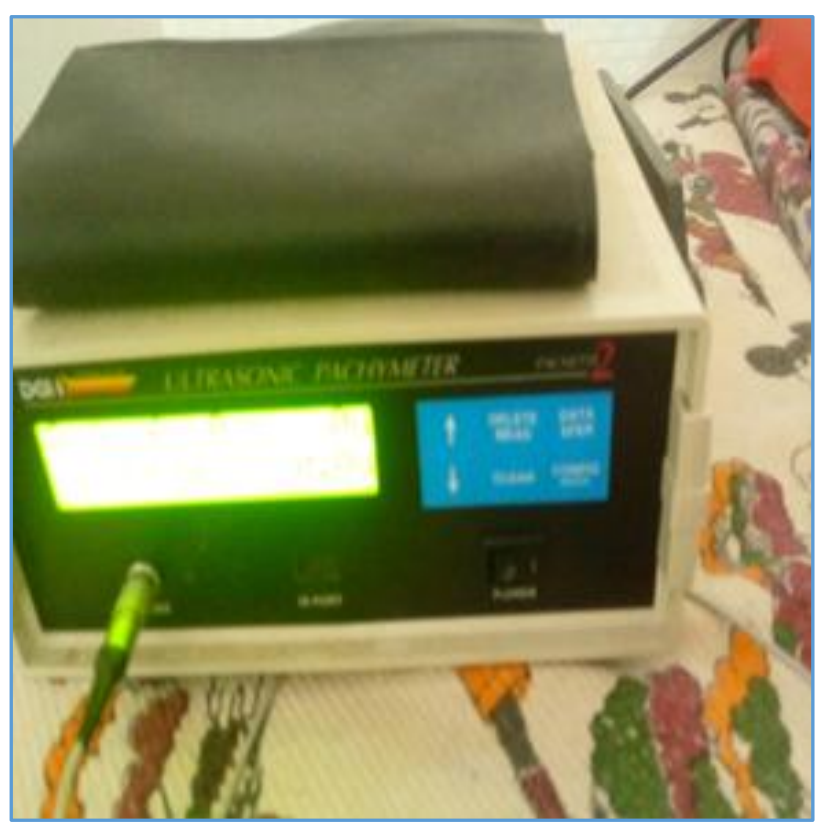

Figure 1. Pachymeter

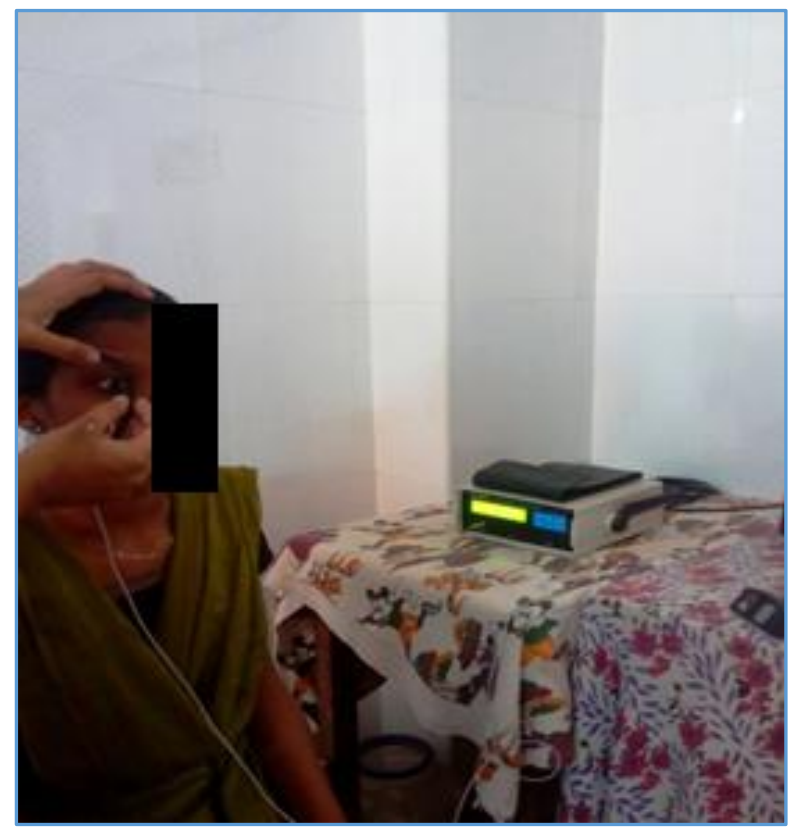

Figure 2. Measuring Central Corneal Thickness

\section{DISCUSSION}

In our study of 300 patients, average central corneal thickness was 545 microns (SD +/- 34 Microns) with a range of 410 - 590 microns. Among 300 patients studied, we did not obtain any correlation between various refractive errors (spherical equivalent) and central corneal thickness.(1-3)

In our study of 160 patients among 300 patients, Myopes average corneal thickness was 541 micrometres (SD 31).(1) Similar corneal thickness in both emmetropes and myopes. In Literature, Tokoro and co-workers, myopic cornea was found to be $0.018 \mathrm{~mm}$ thinner than normal controls. Cho and Lam found that Central Corneal Thickness decreases with increasing age, but not with refractive error or corneal curvatures.(1)

In our study of 32 patients among 300 patients had high myopia, observed average corneal thickness was 537 micrometres (SD 27). Von Bahr G in his study of measurement of corneal thickness found slightly thinner corneas in high myopes. (2)

In our study 48 patients out of 300 patients studied had myopic astigmatism with average corneal thickness of 512 micrometres (SD 37); comparatively had thinner corneas than other refractive errors. This correlates with Von Bahr G's study measurements of the thickness of cornea.(2)

32 patients of 300 patients were hypermetropic astigmatic individuals with average corneal thickness of 532 micrometres, SD (30).

60 patients of 300 patients were hypermetropes with average corneal thickness of 545 micrometres with SD (34).

No significant difference was seen between right and left eyes. No difference between genders (Male and Female patients) was observed.

Corneal pachymetry is essential prior to a refractive surgery procedure for ensuring sufficient corneal thickness to prevent abnormal bulging of the corneal ectasia.(4-9) In preoperative assessment of candidates for LASIK residual, stromal thickness of 250 - 300 microns must be ensured. Also optical zone in keratorefractive procedures. Measurement of IOP may be affected by CCT. Corneal pachymetry is useful in 
assessing indirectly the function of the endothelium.(4) CCT with $>640$ microns in patients with endothelial dysfunction is associated with greater risk of postoperative corneal decompensation.

CCT is higher in young patients, in diabetics.(3) There is no correlation with refractive errors and hypertensive patients.

\section{CONCLUSION}

In our study among 300 patients, no correlation was observed between various refractive errors of age group 10 - $40 \mathrm{yrs}$. and central corneal thickness.(1-3) There was slightly thinner cornea in high myopes and in myopic astigmatism.(4) Review of literature also indicates that decrease in corneal thickness in myopic patients is due to anterior segment change, as eyeball is elongated and emmetropes too had thinner Central Corneal Thickness. $(4,5)$ Corneal thickness assist in determining various ophthalmic medical and surgical treatment such as corneal transplant, refractive surgical procedures, contact lens wear to prevent postoperative corneal thinning. In high myopes more stromal ablation is needed to achieve optical correction, which renders the postoperative cornea even thinner. The corneal flap thickness decreased in thinner corneas and the visual outcomes was slightly worse in thin corneal flap groups. For high myopes, refractive procedures for myopic correction other than LASIK (laser in situ keratomileusis) might be more important. $(6,7,8,9)$ The use of Ultrasonic Pachymetry in keratoconic cornea is questionable because of change in refractive index (inferior apical cone) when compared with orbscan. ${ }^{10,11)}$

\section{REFERENCES}

[1] Chang SW, Tsai IL, Hu FR, et al. The cornea in young myopic adults. Br J ophthalmol 2001;85:916-20.
[2] Bahr VG. Measurements of the thickness of cornea. Arch ophthalmol 1948;26:247-65.

[3] Patwardhan AA, Khan M, Mollan SP, et al. The importance of central corneal thickness measurements and decision making in general ophthalmology clinics: a masked observational study. BMC Ophthalmol 2008;8:1.

[4] Sanchis-Gimeno JA, Palanca-sanfrancisco JM, GarciaLazaro S, et al. The effect of anesthetic eye drop instillation on the distribution of corneal thickness. Cornea 2013;32(5):e102-5.

[5] Pedersen L, Hjortdal J, Ehlers N. Central corneal thickness in high myopia. Acta Ophthalmol Scand 2005;83(5):539-42.

[6] Condon PI, O'keefe M, Binder PS. Long-term results of laser in situ keratomileusis for high myopia: risk for ectasia. J cataract Refractsurg 2007;33(4):583-90.

[7] Price FW, Koller DL, Price MO. Central corneal pachymetry in patients undergoing laser in situ keratomileusis. Ophthalmology 1999;106(11):221620.

[8] Argento C, Cosentino MJ, Tytiun A, et al. Corneal ectasia after laser in situ keratomileusis. J Cataract Refract surg 2001;27(9):1440-8.

[9] Pallikaris IG, Kymionis GD, Astyrakakis NI. Corneal ectasia induced by laser in situ keratomileusis. J Cataract Refract Surg 2001;27(11):1796-802.

[10] Faramarzi A, Ziai H. Central corneal thickness measurement by ultrasound versus orbscan II. J Ophthalmic vis Res 2008;3(2):83-6.

[11] Hashemi H, Roshani M, Mehravaran S, et al. Effect of corneal thickness on the agreement between ultrasound and orbscan II pachymetry. J Cataract Refract Surg 2007;33(10):1694-700. 